\title{
Crustacean-acanthocephalan interaction and host cell-mediated immunity: parasite encapsulation and melanization
}

\author{
Bahram Sayyaf Dezfuli ${ }^{1}$, Edi Simoni $^{1}$, Laura Duclos $^{2}$ and Emanuele Rossetti ${ }^{1}$ \\ ${ }^{1}$ Department of Biology and Evolution, University of Ferrara, St. Borsari, 46, 44100 Ferrara, Italy; \\ ${ }^{2}$ Nature's Variety, P.O. Box 29345, Lincoln, NE 68529, USA
}

Key words: Pomphorhynchus laevis, Echinogammarus stammeri, host immunity, parasite melanization

\begin{abstract}
Host-parasite interactions of Pomphorhynchus laevis (Müller, 1776) in naturally infected amphipod, Echinogammarus stammeri (Karaman), from the Brenta River (northern Italy) are described. A fully developed acanthocephalan larva occupies a large portion of an amphipod's haemocoelic space; thus, the parasite frequently induces displacement of host digestive tract and other internal organs. However, no apparent damage to the host's internal structures was observed. Within the haemocoel of $E$. stammeri, each larva of $P$. laevis is surrounded with a membranous layer, formed by microvilli, which maintains intimate contact with the amphipod's internal organs and haemocytes. Three types of circulatory haemocytes were identified based upon their distinct appearance: hyaline cell, semi-granular cell and granular cell. Echinogammarus stammeri haemocytes surrounded acanthocephalan larvae and in some instances a partially and/or totally melanized $P$. laevis larva was noticed. Interestingly, no melanized larvae were found in E. stammeri parasitized with other acanthocephalans namely Echinorhynchus truttae (Schrank, 1788), Polymorphus minutus (Goeze, 1782) and Acanthocephalus clavula (Dujardin, 1845).
\end{abstract}

Acanthocephalans infecting freshwater fishes are known to utilize primarily crustaceans as their intermediate hosts. Some effects of acanthocephalan larvae on this group of arthropods are changes in host behaviour (Wellnitz et al. 2003, Baldauf et al. 2007, Perrot-Minnot et al. 2007), reproduction (Oetinger 1987, Dezfuli and Giari 1999, Dezfuli et al. 1999), respiration (Bentley and Hurd 1996), immune reactivity (Volkmann 1991, Moret et al. 2007), response to wavelength (Benesh et al. 2005), and survival (Duclos et al. 2006).

Many parasites, including several species of veterinary and medical significance, have life cycles that require development, reproduction, or both within invertebrate hosts (Loker 1994). Investigations into the immune defences of arthropods have shown that although arthropods lack an adaptive immune response, they do exhibit efficient and rapid defence processes such as exoskeleton repair and foreign body recognition, inactivation and elimination (Thörnqvist and Söderhäll 1997). Inactivation and elimination of foreign bodies are part of a cellular defence reaction and are related to the activation of the phenoloxidase cascade, a biochemical process involved in the melanization pathway (Cerenius and Söderhäll 2004). Phenoloxidase has the capacity to adhere to the surface of microorganisms, fungi and parasites. Attachment leads to melanin forming on the surface of foreign body or invading organism (Cerenius and Söderhäll 2004). Nevertheless, deposition of melanin represents a unique, innate immune response in the phylum Arthropoda (Christensen et al. 2005).

Aquatic crustaceans are in intimate contact with their environment, especially in intensive aquaculture sys- tems which tend to accumulate high levels of viruses and bacteria (Jiravanichpaisal et al. 2006). Further, melanotic encapsulation of fungi and bacteria in crustaceans are frequently reported from aquaculture systems; a review was provided by Edgerton et al. (2002). In contrast, there is a lack of data on melanization of bacteria and fungi in crustacean populations from natural habitats. This paucity of data extends to melanization of metazoan parasites (Kostadinova and Mavrodieva 2005). Encapsulation seems to be a cellular immune response restricted to invertebrates as a defence mechanism against foreign organisms or objects that are too large for phagocytosis by individual haemocytes. However, haemocytes are involved in the process because encapsulation results in a multilayered, overlapping sheath of haemocytes around the invader (Jiravanichpaisal et al. 2006).

In Echinogammarus stammeri (Karaman), a fully developed Pomphorhynchus laevis (Müller, 1776) cystacanth occupies a large portion of haemocoel and induces displacement and often constriction of the host internal organs. This phenomenon was noticed in the same species of crustacean parasitized with the acanthocephalans Acanthocephalus clavula (Dujardin, 1845) (see Dezfuli et al. 1994), Polymorphus minutus (Goeze, 1782) (see Dezfuli and Giari 1999) and Echinorhynchus truttae (Schrank, 1788) (unpublished data). It was noticed also in the isopod Asellus aquaticus infected with the acanthocephalan Acanthocephalus anguillae (see Dezfuli 2000). Each P. laevis larva is covered with a membranous layer formed by microvilli. The same type of layer was observed also for Moniliformis moniliformis 
(Bremser, 1811) in its cockroach intermediate host $\mathrm{Pe}$ riplaneta americana (L.) (see Volkmann 1991). The origin of this layer was discussed in detail in review published by Taraschewski (2000). Apparently, this membranous layer functions to protect developing larvae from host cellular responses (Holt 1989) and, according to Erasmus (1967), this layer may compose part of the host-parasite interface because it maintains intimate contact with the host organs and fluids.

During the 7 years of investigation, 50,000 E. stammeri were examined, of which more than $24 \%$ were infected with $P$. laevis. Of the 18,710 parasite larvae recovered, only 32 were partially or totally melanized (Dezfuli et al. 1999). In the same period, E. stammeri was found to be infected with other acanthocephalans (A. clavula, P. minutus and E. truttae), but no melanized larvae of these species were encountered. This investigation focuses on the ultrastructural features of the $E$. stammeri-P. laevis interface. The primary aim of this study is to compare and discuss the potential reasons for various protection mechanisms against the cellular response of the same intermediate host adopted by four acanthocephalan parasites.

\section{MATERIALS AND METHODS}

Amphipods were collected from the Brenta River (Carturo locality, Padua, northern Italy) during several sampling periods conducted in 2006. The amphipods were collected using a dip net (mesh size, $3 \mathrm{~mm}$ ) in shallow water near the bank, both from overhanging vegetation and below the waterline. About 850 specimens of Echinogammarus stammeri were collected. For microscopical purposes, some amphipods were immediately examined for larval helminths while still alive. In each sample, specimens of both infected and uninfected E. stammeri were fixed in $2.5 \%$ glutaraldehyde buffered at $\mathrm{pH} 7.2$ in $0.1 \mathrm{M}$ sodium cacodylate for $3 \mathrm{~h}$. In the laboratory, the bodies of several uninfected amphipods were portioned into small pieces for better embedding. Portions that harboured acanthocephalan larvae were isolated from the rest of the E. stammeri body using a stereomicroscope. These portions were postfixed in $1 \%$ osmium tetroxide in the same buffer for $4 \mathrm{~h}$ before dehydrating in a graded series of ethanol. Finally, these infected samples were transferred to propylene oxide and embedded in an Epon-Araldite mixture. Semi-thin sections $(1.5 \mu \mathrm{m})$ were cut using a Reichert Om U2 ultramicrotome with glass knives and then stained with toluidine blue. Ultra-thin sections were contrasted using a 50\% alcohol-uranyl acetate solution with lead citrate and examined using a Hitachi H-800 electron microscope operated at $80 \mathrm{kV}$. Light micrographs were taken using a Nikon microscope Eclipse 80i.

\section{RESULTS}

Semi-thin sections through the pereionic region of an uninfected individual of E. stammeri show the true position of various internal organs within the amphipod haemocoel (Fig. 1). When fully developed, the cystacanth of $P$. laevis occupies a large portion of the haemocoelic space, inducing a dramatic displacement of the amphipod's internal organs (Fig. 2). The presence of an acanthocephalan larva reduces the luminal space/ diameter of certain internal organs, such as the intestine, digestive caeca and heart (Fig. 2); in many instances they lose their true position, shape, and symmetry within the haemocoel (Fig. 2). In all semi-thin sections of parasitized shrimp stained with toluidine blue, a pale blue region was visible around $P$. laevis body wall (Fig. 4). Under the electron microscope, this region appeared as a membranous layer composed of microvilli (Figs. 5, $6)$. The thickness of this membranous layer was variable. When the $P$. laevis larva was near host organs, the membranous layer was thin (about $1.6 \mu \mathrm{m}$ ) and microvilli were bent. Conversely when the larva was distant from host organs, the membranous layer thickness reached about $8 \mu \mathrm{m}$.

In many instances $P$. laevis larvae were encircled by crustacean haemocytes (Figs. 3, 4). With light microscopy, these cells were observed on the outermost surface of the pale blue region (Fig. 4); in very few cases, haemocytes were found within the thickness of the membranous layer and close to the larval tegument (Fig. 6). In semi-thin sections, these haemocytes appeared as just a few cells, as clumps of cells, or as several layers of cells (Figs. 3, 4). Moreover, three haemocyte cell types were identified in E. stammeri based upon the amount of granules in the cytoplasm: granular, semigranular, and hyaline (see Johansson et al. 2000). Some hyaline cells on the external edge of the membranous layer are shown in Fig. 5, while granular cells are shown in Figs. 5 and 6. Interestingly, in amphipods harbouring few $P$. laevis larvae, not all larvae were encircled with crustacean haemocytes; the cells were mainly found around one or two larvae and the presence of cells often was limited to a portion of larval body only (Fig. 3). Rarely was the whole larva observed to be encircled by E. stammeri haemocytes. Often, residues of disintegrated haemocytes (Fig. 5) as well as intact host haemocytes was noticed (Fig. 6).

During the present survey, 8 (3.9\%) E. stammeri out of 204 infected amphipods harboured a partially (Fig. 7) or completely melanized $P$. laevis larva (Fig. 8). Melanized $P$. laevis occurred alone or in conjunction with non-melanized $P$. laevis (Figs. 7, 8). No melanized larva was encountered when $P$. laevis co-occurred with other acanthocephalan parasites.

Echinogammarus stammeri in the Brenta River is also an intermediate host for the species A. clavula, Polymorphus minutus and Echinorhynchus truttae. However, the prevalence of infection with these acanthocephalans was very low in comparison to $P$. laevis; they were examined with an electron microscope for comparison with $P$. laevis. Each $A$. clavula cystacanth was encased in a thin acellular envelope; thickness ranged from 1.1 to $1.3 \mu \mathrm{m}$ (Fig. 9). This envelope was moderately electron-dense and appeared to be formed by both granular and filamentous materials. Vesicles with vary- 

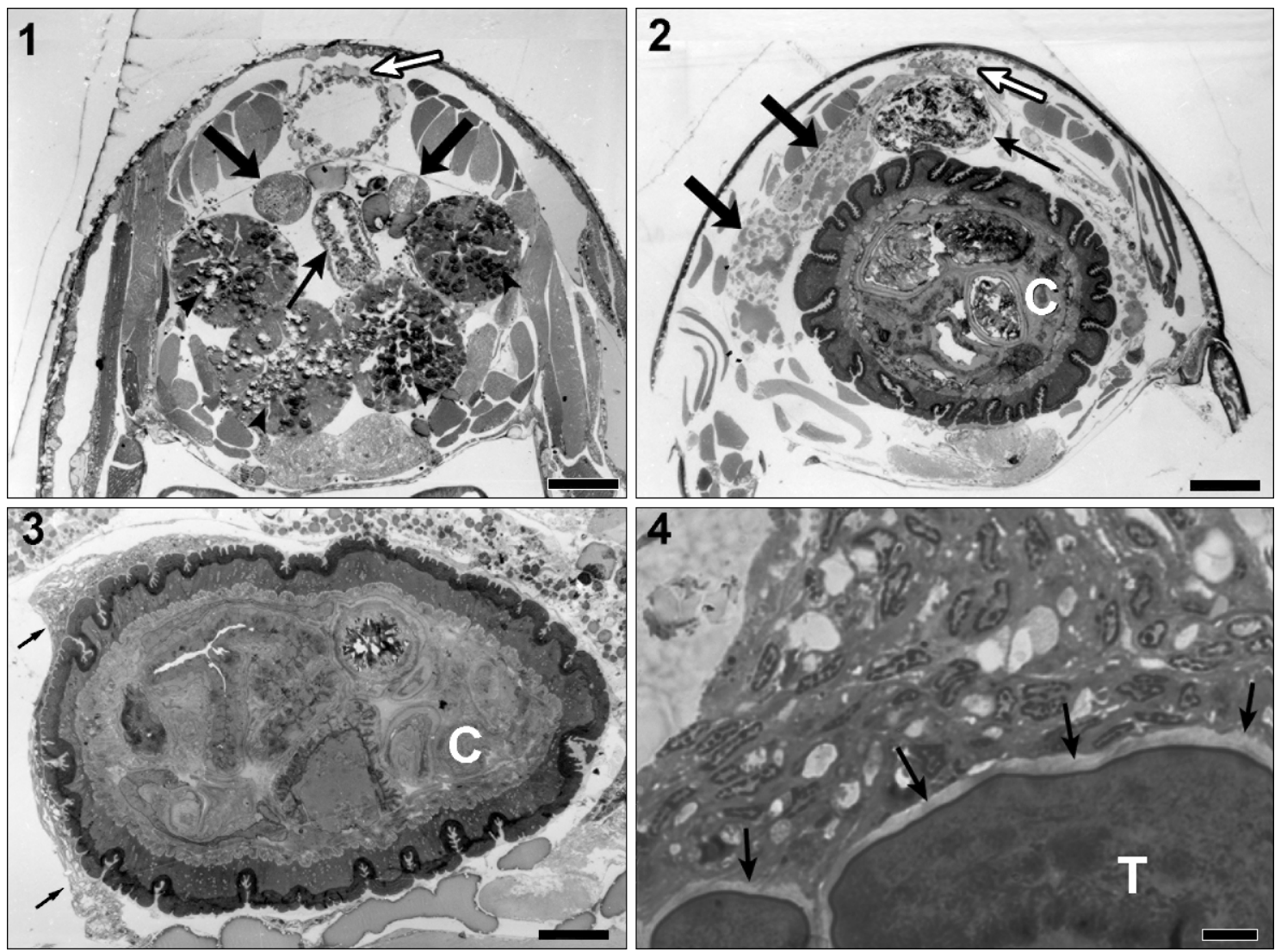

Figs. 1-4. Light micrographs from semi-thin sections of uninfected and parasitized Echinogammarus stammeri. Fig. 1. Uninfected E. stammeri; note the central position of the amphipod intestine (thin arrow), symmetry of the digestive caeca (thick arrows) and gonads (arrowheads) and lumen of the heart (open arrow). Fig. 2. Parasitized amphipod; note the fully developed Pomphorhynchus laevis cystacanth (C) occupying a large portion of the haemocoelic space and induced displacement of the intestine (thin arrow) and digestive caeca (thick arrows) and constriction of the heart (open arrow). Fig. 3. Haemocytes (arrows) of E. stammeri encircling approximately half of the cystacanth body (C). Fig. 4. High magnification of interface region between several haemocyte layers and parasite tegument (T) with arrows showing the pale blue region. Scale bars: Fig. $1=135 \mu \mathrm{m}$; Fig. 2 $=180 \mu \mathrm{m}$; Fig. $3=110 \mu \mathrm{m}$; Fig. $4=10 \mu \mathrm{m}$.

ing shapes and profiles occurred within the envelope (Fig. 10). In some regions, the envelope adhered to the outer surface of the A. clavula cystacanth (Figs. 9, 10). Echinogammarus stammeri haemocytes were commonly observed in contact with the external surface of the cystacanth envelope (Figs. 9, 10); cells were partially or completely disintegrated (Fig. 9) or were intact (Fig. 10). The larvae of P. minutus and E. truttae were surrounded with an acellular envelope similar to that observed for $A$. clavula. Of note, no melanized larvae of A. clavula, P. minutus or E. truttae were seen within the haemocoel of E. stammeri.

\section{DISCUSSION}

As reported here, Pomphorhynchus laevis induced displacement and constriction of host internal organs, becoming more pronounced with increasing degree of larval development. Fully developed cystacanths occupied a very large portion of the amphipod's haemocoelic space. The same finding was reported in the isopod
Asellus intermedius (Forbes) parasitized with Acanthocephalus dirus (Van Cleave, 1931) (Oetinger and Nickol 1981) and in Asellus aquaticus (L.) infected with Acanthocephalus anguillae (Müller, 1780) (see Dezfuli et al. 1994). Displacement and constriction of internal organs were also noticed in the amphipod Hyalella azteca (Saussure) experimentally infected with Leptorhynchoides thecatus (Linton, 1891) (see Spaeth 1951). According to Spaeth, the larvae of $L$. thecatus interfered with the host's metabolism. This suggestion might hold true also for Pomphorhynchus laevis-infected Echinogammarus stammeri.

Parasites with complex life-cycle that develop within an invertebrate host must ensure survival by evading the host immune response (Loker 1994). Concerning Arthropoda, haemocytes play a critical role in the immune reaction, including recognition, encapsulation, phagocytosis and melanization (Johansson et al. 2000). Within the haemocoel, parasite encapsulation is common to nearly all arthropods (Christensen et al. 2005, Jira- 

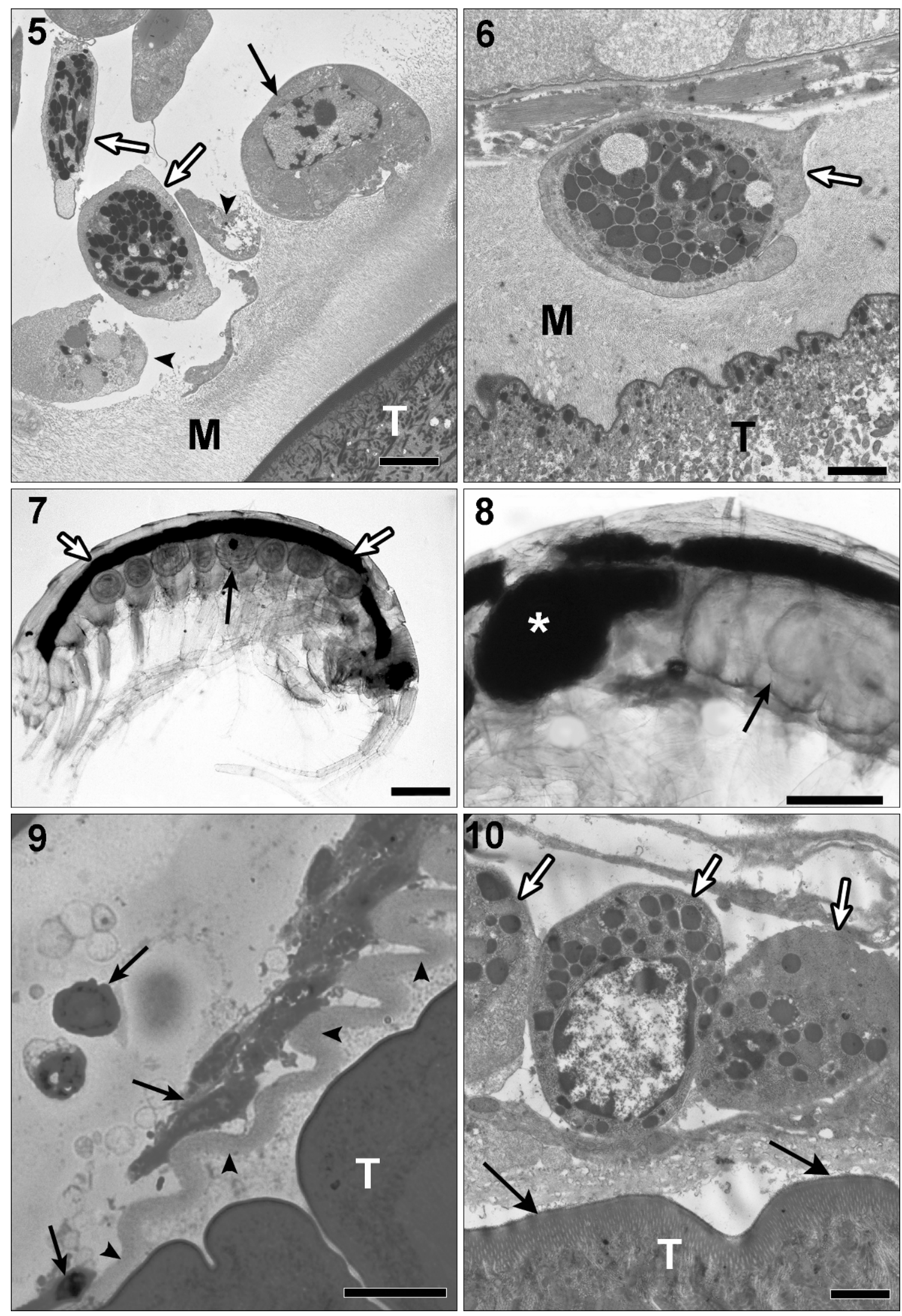
vanichpaisal et al. 2006). Congregation of arthropod haemocytes around a foreign body is one of the first host responses to an invader (Johansson et al. 2000, Söderhäll et al. 2005). Data on arthropod immune responses against metazoan parasites referred mainly to insects; information on crustaceans is very scarce. Nevertheless, the data suggest that parasites may have the ability to circumvent crustacean immune defences (Rigaud and Moret 2003). For example, in the amphipod Gammarus aequicauda (Martynov) infected with metacercariae of four trematode species (Microphallus hoffmanni Rebecq, 1964, M. papillorobustus Rankin, 1940, Maritrema subdolum Jägerskiöld, 1909 and Leviseniella propinqua Jägerskiöld, 1907), three trematodes always encyst in the abdomen while only one trematode $(M$. papillorobustus) is able to occasionally encyst in the cerebroid ganglion. Moreover, cases of melanization concern almost exclusively metacercariae found in the cerebroid ganglion (Thomas et al. 2000). As it was noted previously, a very small proportion of the $P$. laevis larvae population was found to be melanized. This same finding was reported for larvae of Moniliformis moniliformis in the cockroach, Periplaneta americana (Schaefer 1970, Brennan and Cheng 1975). According to several authors, this phenomenon may occur as a result of the envelope and/or membranous layer inhibiting parasite melanization (Robinson and Strickland 1969, Lackie and Rotheram 1972, Brennan and Cheng 1975, Lackie and Lackie 1979, Volkmann 1991). It has been proposed that a small proportion of larvae which pass through arthropod intestinal wall to the haemocoel may be moribund or weak; alternatively larvae may be weak following haemocoel penetration and only these moribund/weak are able to be melanized (Robinson and Strickland 1969, Lackie 1972).

The origin of the membranous layer, often referred to as the envelope, around larvae of various acanthocephalan species occupying the haemocoel of its arthropod intermediate host has been long the subject of controversy (Wanson and Nickol 1973). Some researchers have attributed the origin of this structure to the arthropod's intestinal tissue (Crompton 1964), or else to the host haemocytes (Mercer and Nicholas 1967, Ravin- dranath and Anantaraman 1977). Other authors have suggested that the envelope is formed wholly by the parasite (Volkmann 1991, Taraschewski 2000). Observations by transmission electron microscopy have attributed most if not all of the envelope to the acanthocephalan larva with residues of disintegrated haemocytes contributing to thickness (Rotheram and Crompton 1972, Dezfuli et al. 1994, Dezfuli and Giari 1999, Dezfuli 2000). Pomphorhynchus laevis as well as Moniliformis moniliformis (see Volkmann 1991) and Macracanthorhynchus hirudinaceus (Pallas, 1781) (see Zhao and Wang 1992) possess a type envelope or membranous layer which is not considered a "rigid" barrier against the movement of the arthropod haemocytes. Thus, some host immune cells are able to penetrate into the membranous layer and release its contents (e.g., melanin) within the vicinity of larval tegument.

In the Brenta River, E. stammeri is also the intermediate host of $A$. clavula, P. minutus and E. truttae. These helminths represent a group of acanthocephalan species that possess a four-layered shell around each egg. Some of these shell layers persist as a "rigid" envelope covering the larva (Lackie and Lackie 1979, Holt 1989). A probable protective function against the host's cellular response has been attributed to this envelope (Rotheram and Crompton 1972, Lackie and Lackie 1979, Dezfuli et al. 1994, Dezfuli and Giari 1999, Dezfuli 2000). Thus, it is reasonable to suggest that the lack of melanized larva of $P$. minutus, E. truttae and A. clavula is exclusively due to this "rigid" envelope persisting from the egg stage. Furthermore, the frequent occurrence of disintegrated haemocytes on external surface of the envelope around the three acanthocephalan species is a testimony of unsuccessful E. stammeri cellular responses.

The present study on E. stammeri defensive response to $P$. laevis is the first for this acanthocephalan taxon, supplying concrete data about the cellular interface between amphipod haemocytes and acanthocephalans. Indeed, this report provides a unique opportunity for comparative studies investigating the protective reaction of different acanthocephalan parasites within the same crustacean species.

\footnotetext{
Figs. 5-10. Light (Figs. 7-9) and transmission electron (Figs. 5, 6, 10) micrographs of host-parasite interface region of two acanthocephalan parasites and of Pomphorhynchus laevis melanized larvae. Fig. 5. Presence of some haemocytes outside the membranous layer (M) on the surface of cystacanth tegument (T); note granular cells (empty arrows), hyaline cell (arrow) and disintegrated cells (arrowheads). Fig. 6. Granular cell (open arrow) within the thickness of the membranous layer (M) in proximity of larval tegument (T). Fig. 7. Echinogammarus stammeri with eight $P$. laevis larvae, of which only one larva (arrow) is partially melanized; note haemocoelic space occupied by the larvae and displacement of the host gut (empty arrows). Fig. 8. Two $P$. laevis larvae and the larva with semi-everted neck is totally melanized (white asterisk) while the larva (arrow) on right side of the photo appears normal. Fig. 9. Semi-thin section of Acanthocephalus clavula larva inside the amphipod haemocoel; note an envelope (arrowheads) separates haemocytes (arrows) from the parasite tegument (T). Fig. 10. Presence of haemocytes (empty arrows) on external surface of the envelope of $A$. clavula and some locations of the envelope adhering (arrows) to the larval tegument (T). Scale bars: Fig. $5=4 \mu \mathrm{m}$; Fig. $6=2.5 \mu \mathrm{m}$; Fig. $7=1,100 \mu \mathrm{m}$; Fig. $8=600 \mu \mathrm{m}$; Fig. $9=20 \mu \mathrm{m}$; Fig. $10=2 \mu \mathrm{m}$.
} 


\section{REFERENCES}

BAldauf S.A., ThÜNKEn T., FrOMmen J.G., BAKKeR T.C.M., HeuPEl O., KullmanN H. 2007: Infection with acanthocephalan manipulates an amphipod's reaction to a fish predator's odours. Int. J. Parasitol. 37: 61-65.

BENESH D.P., DuClOS L.M., NiCKOL B.B. 2005: The behavioural response of amphipods harbouring Corynosoma constrictum (Acanthocephala) to various components of light. J. Parasitol. 91: 731-736.

BENTLEY C.R., HURD H. 1996: Carbohydrate titres in the haemolymph and midgut of Gammarus pulex infected with the acanthocephalan Pomphorhynchus laevis. J. Helminthol. 70: 103107.

BRENNAN B.M., ChENG T.C. 1975: Resistance of Moniliformis dubius to the defence reactions of the American cockroach Periplaneta americana. J. Invertebr. Pathol. 26: 65-73.

CERENIUS L., SÖDERHÄLl K. 2004: The prophenoloxidaseactivating system in invertebrates. Immunol. Rev. 198: 116126.

Christensen B.M., Li J., Chen C., NAPPI A.J. 2005: Melanization immune responses in mosquito vectors. Trends Parasitol. 21: $192-199$.

CROMPTON D.W.T. 1964: The envelope surrounding Polymorphus minutus (Goeze, 1782) (Acanthocephala) in its development in the intermediate host, Gammarus pulex. Parasitology 54: 721-735.

DEZFULI B.S. 2000: Host-parasite interface between Asellus aquaticus (Isopoda) and larvae of Acanthocephalus anguillae (Acanthocephala). Folia Parasitol. 47: 154-156.

DEZFULI B.S., GIARI L. 1999: Amphipod intermediate host of Polymorphus minutus (Acanthocephala), parasite of water birds, with notes on ultrastructure of host-parasite interface. Folia Parasitol. 46: 117-122.

DEZFULI B.S., BOSI G., ROSSI R. 1994: Fine structure of the envelope surrounding the cystacanth of Acanthocephalus clavula (Acanthocephala) in its intermediate host Echinogammarus stammeri (Amphipoda). Trans. Am. Microsc. Soc. 113: 34 42.

Dezfuli B.S., Rossetti E., Bellettato C.M., MAYNARD B.J. 1999: Pomphorhynchus laevis in its intermediate host Echinogammarus stammeri in the River Brenta, Italy. J. Helminthol. 73: 95-102.

DuCLOS L.M., BRADFORD J.D., NiCKOL B.B. 2006: Virulence of Corynosoma constrictum (Acanthocephala: Polymorphidae) in Hyalella azteca (Amphipoda) throughout parasite ontogeny. J. Parasitol. 92: 749-755.

EDGERTON B.F., EVANS L.H., STEPHENS F.J., OVERSTREET R.M. 2002: Synopsis of freshwater crayfish diseases and commensal organisms. Aquaculture 206: 57-135.

ERASMUS D. 1967: The host-parasite interface of Cyathocotyle bushiensis Khan, 1962 (Trematoda: Strigeoidea) II. Electron microscope studies of the tegument. J. Parasitol. 53: 703-714.

HOLT R.H.F. 1989: Hymenolepis diminuta utilizes the envelope surrounding Moniliformis moniliformis in order to survive in the cockroach host. J. Parasitol. 75: 160-162.

JiRAVANIChPaisal P., LeE B.L., SöDERHÄLl K. 2006: Cellmediated immunity in arthropods: hematopoiesis, coagulation, melanization and opsonization. Immunobiology 211: 213-236.

JoHANSSON M.W., KeYSER P., SRITUNyAluCKSANA K., SÖDERHÄLL K. 2000: Crustacean haemocytes and haematopoiesis. Aquaculture 191: 45-52.

KostadinOVA A., MAVRODIEVA R.S. 2005: Microphallids in Gammarus insensibilis Stock, 1966 from a Black Sea lagoon: host response to infection. Parasitology 131: 347-354.
LACKIE J.M. 1972: The course of infection and growth of Moniliformis dubius (Acanthocephala) in the intermediate host $\mathrm{Pe}$ riplaneta americana. Parasitology 64: 95-106.

LACKIE J.M., ROTHERAM S. 1972: Observations on the envelope surrounding Moniliformis dubius (Acanthocephala) in the intermediate host. Parasitology 65: 303-308.

LACKIE A.M., LACKIE J.M. 1979: Evasion of the insect immune response by Moniliformis dubius (Acanthocephala): further observations on the origin of the envelope. Parasitology 79: 297-301.

LOKER E.S. 1994: On being a parasite in an invertebrate host: a short survival course. J. Parasitol. 80: 728-747.

MERCER E.H., NichOLAS W.L. 1967: The ultrastructure of the capsule of the larval stages of Moniliformis dubius (Acanthocephala) in the cockroach Periplaneta americana. Parasitology 57: 169-174.

Moret Y., Bollache L., Wattier R., Rigaud T. 2007: Is the host or the parasite the most locally adapted in an amphipodacanthocephalan relationship? A case study in a biological invasion context. Int. J. Parasitol. 37: 637-644.

OETINGER D.F. 1987: Effects of Acanthocephalus dirus (Acanthocephala) on morphometrics and reproduction of Caecidotea intermedius (Crustacea: Isopoda). Trans. Am. Microsc. Soc. 16: 240-248.

OETINGER D.F., NICKOL B.B. 1981: Effects of acanthocephalans on pigmentation of freshwater isopods. J. Parasitol. 67: 672684.

PERROT-MinNOT M.-J., KALdONSKI N., CÉZILLy F. 2007: Increased susceptibility to predation and altered anti-predator behaviour in an acanthocephalan-infected amphipod. Int. J. Parasitol. 37: 645-651.

RAVINDRANATH M.H., ANANTARAMAN S. 1977: The cystacanth of Moniliformis moniliformis (Bremser, 1811) and its relationship with the haemocytes of the intermediate host $(\mathrm{Pe}$ riplaneta americana). Z. Parasitenkd. 53: 225-237.

RIGAUD T., MORET Y. 2003: Differential phenoloxidase activity between native and invasive gammarids infected by local acanthocephalans: differential immunosuppression? Parasitology 127: 571-577.

ROBINSON E.S., STRICKLAND B.C. 1969: Cellular response of Periplaneta americana to acanthocephalan larvae. Exp. Parasitol. 26: 384-392.

ROTHERAM S., CROMPTON D.W.T. 1972: Observations on the early relationship between Moniliformis dubius (Acanthocephala) and the haemocytes of the intermediate host, $\mathrm{Pe}$ riplaneta americana. Parasitology 64: 15-21.

SCHAEFER P.W. 1970: Periplaneta americana (L.) as intermediate host of Moniliformis moniliformis (Bremser) in Honolulu, Hawaii. Proc. Helminthol. Soc. Wash. 37: 204-207.

SÖDERHÄLl I., KiM Y., JiRAVANICHPAISAL P., LEE S., SÖDERHÄLL K. 2005: An ancient role of a prokineticin domain in invertebrate haematopoiesis. J. Immunol. 174: 6153-6160.

SPAETH F.W. 1951: The influence of acanthocephalan parasites and radium emanations on the sexual characters of Hyalella (Crustacea: Amphipoda). J. Morphol. 88: 361-383.

TARASCHEWSKI H. 2000: Host-parasite interactions in Acanthocephala: a morphological approach. Adv. Parasitol. 46: 1179.

ThOmas F., Guldner E., Renaud F. 2000: Differential parasite (Trematoda) encapsulation in Gammarus aequicauda (Amphipoda). J. Parasitol. 86: 650-654.

THÖRNQVIST P.-O., SÖDERHÄLL K. 1997: Crustacean immune reactions, a short review. In: T.W. Flegel and I.H. MacRae 
(Eds.), Disease in Asian Aquaculture III. Fish Health Section, Asian Fisheries Society, Philippines, pp. 203-218.

VOLKMANN A. 1991: Localization of phenoloxidase in the midgut of Periplaneta americana parasitized by larvae of Moniliformis moniliformis (Acanthocephala). Parasitol. Res. 77: 616-621.

WANSON W.W., NICKOL B.B. 1973: Origin of the envelope surrounding larval acanthocephalans. J. Parasitol. 59: 1147.

Received 24 October 2007
Wellnitz T.A., Giari L., MAYNARD B., DeZfuli B.S. 2003: A parasite spatially structure in host population. Oikos 100: 263-268.

ZHAO B., WANG M.X. 1992: Ultrastructural study of the defence reaction against the larvae of Macracanthorhynchus hirudinaceus in laboratory-infected beetles. J. Parasitol. 78: 10981101.

Accepted 27 December 2007 